\title{
Variation Characteristics of Stable Isotopes of Precipitation and Water Vapor Sources in the Monsoon Margin Region: A Case Study of the Binggou River Basin
}

\author{
Junju Zhou ${ }^{1,2}$, Meihua Huang ${ }^{1 *}$, Li Lei ${ }^{3}$, Guofeng Zhu ${ }^{1,4}$, Lanying Wang ${ }^{5}$, \\ Guoshuang Chong ${ }^{6,7}$, Juan Xiang ${ }^{1}$, Wei Feng ${ }^{1}$ \\ ${ }^{1}$ College of Geography and Environmental Science, Northwest Normal University, Lanzhou, China \\ ${ }^{2}$ Gansu Engineering Research Center of Land Utilization and Comprehension Consolidation, Lanzhou, China \\ ${ }^{3}$ Shiyang River Basin Water Resources Bureau of Gansu Province, Wuwei, China \\ ${ }^{4}$ State Key Laboratory of Cryosphere Sciences, Northwest Institute of Eco-Environment and Resources, \\ Chinese Academy of Sciences, Lanzhou, China \\ ${ }^{5}$ The Administrative center for China's Agenda 21, Beijing, China \\ ${ }^{6}$ University of the Chinese Academy of Sciences, Beijing, China \\ ${ }^{7}$ Research Center for Eco-Environmental Sciences, Chinese Academy of Sciences, State Key Laboratory \\ of Urban and Regional Ecology, Beijing, China
}

Received: 30 May 2019

Accepted: 21 August 2019

\begin{abstract}
The Binggou River Basin in the eastern part of the Qilian Mountains, located at the edge of a monsoon region, is the research object of this paper. The isotope technique and HYSPLIT 4.9 model were used to study the variation characteristics of the stable isotopes of precipitation and the source of water vapor in this area. The results show that the slope and intercept of the meteoric water line in the Binggou River Basin are significantly lower than those of the global meteoric water line and slightly lower than those of the meteoric water line in northwest China, and the slope and intercept of the meteoric water line in summer and autumn are obviously smaller than they are in winter and spring. The $\delta^{18} \mathrm{O}$ of precipitation is enriched in the warm season, and this obvious temperature effect (greater than $0^{\circ} \mathrm{C}$ ) masked the embodiment of the precipitation effect to some extent. There are great differences in the circulation systems that control the water vapor sources of precipitation in different seasons, and the westerly circulation that carries the water vapor has the greatest impact on Binggou River Basin precipitation, with an average proportion of $53 \%$. The southwestern monsoon and southeastern monsoon also influence the summer precipitation. When the water vapor from the surrounding oceans and lakes reaches the monsoon marginal area in different seasons, the properties of the air mass
\end{abstract}

*e-mail: 18409208568@163.com 
change significantly, showing a significant seasonal effect on the precipitation value of $\delta^{18} \mathrm{O}$ and the $\delta \mathrm{D}$. The seasonal fluctuation characteristics of the stable isotopes of precipitation and their relationship with the temperature, as well as the complex water vapor recharge sources in the Binggou River Basin, show the characteristics of a transition from the eastern monsoon region to the northwestern arid region.

Keywords: atmospheric precipitation, stable isotope, Binggou River Basin, monsoon margin, water vapor source

\section{Introduction}

As important components of natural water, stable isotopes are very sensitive to corresponding environmental changes, although the content of stable isotopes is very small [1]. Precipitation is an important link in the process of a water cycle. The characteristics of the stable isotopes of precipitation are closely related to the meteorological conditions for precipitation formation and the initial state of a water vapor source area, and they constitute the most direct and powerful tool for studying the process of precipitation [2-4]. We can use the analysis of their composition changes and size ratio to help people understand the source and cycle history of atmospheric water vapor in different geographical areas [5-6].

Dansgaard was the first to observe and study the stable isotopes of precipitation in 1952. The classical temperature effect and the precipitation effect were proposed in 1964, which laid the foundation for isotope hydrology. Since then, many countries and regions in the world have carried out a large number of modern precipitation isotope monitoring studies and have achieved a range of research results [7-12]. Friedman [13] first discovered the phenomenon of a decrease of the slope of the Meteoric Water Line due to evaporation in the process of precipitation; Yuri V Dublyansky et al. [14] systematically studied the isotope composition of precipitation in the Crimean Peninsula and found that, in the study area, it was not always controlled by the local temperature and precipitation; the local environment and other factors also had some influence. In the Asian Summer Monsoon region, the isotopic composition of precipitation is strongly related to the height and the convection of clouds in the dominant water vapor source and its transport paths [15]. After observing changes in the stable isotope composition of precipitation in mid-latitude coastal areas, Li [16] found that changes in the stable isotope composition of precipitation in mid-latitude coastal areas were related to atmospheric circulation and water vapor sources. Gh. Jeelania [17] conducted studies on the effects of water vapor transport in the Indian monsoon region, indicating that water vapor depletion mainly occurs in different water vapor source regions. After more than 50 years of development and accumulation, the current research on precipitation isotopes is no longer limited to the analysis of the impact of local meteorological factors (temperature, precipitation, relative humidity, etc.) on the stable isotopes of precipitation, but it also includes the analysis of the effects of large-scale atmosphere circulation and water vapor transport on the seasonal variation of precipitation isotopes [18-19]. The study of the stable isotopes of precipitation is therefore maturing.

The study initiated research on the environmental isotopes of Mount Everest in 1966 [20]. A series of studies were subsequently carried out on precipitation isotopes in the Qinghai-Tibet alpine region [21-23]. The isotopes and the temperature in the non-monsoon region of the Northern Qinghai-Tibet Plateau are significantly correlated. This indicated a strong temperature effect and a negative correlation with altitude, which also demonstrated the effect of temperature on stable isotopes [24]. A certain correlation between the isotope value and the temperature in the central transitional zone of the Qinghai-Tibet Plateau was also found, but it was not very significant [25]. There was an inevitable connection between the stable isotopes of precipitation in the southern monsoon region of the Qinghai-Tibet Plateau and the water vapor transport route. The precipitation isotope value was greatly reduced at the beginning of the summer monsoon, showing the precipitation effect. Additionally, the temperature effect was not obvious [26]. In the northeastern part of the eastern monsoon region and most of northern China, the water vapor is mostly from sources with different hydrogen and oxygen stable isotope ratios [27], and the precipitation has undergone a certain evaporation process, so its precipitation slope is less than the global precipitation standard value [28]. The weighted average of the $\delta^{18} \mathrm{O}$ and the $\delta \mathrm{D}$ of precipitation is depleted, and temperature is an important factor affecting the change of precipitation $\delta^{18} \mathrm{O}$. The precipitation effect only existed in summer, indicating that the summer monsoon can reach these two areas in summer [29]. The southern region of the eastern monsoon region is closer to the ocean water vapor recharge area. The dynamic fractionation of the hydrogen and oxygen stable isotopes is not strong, and the local meteoric water line is close to the global meteoric water line. The stable isotopes of precipitation in this area have obvious precipitation and anti-temperature effects, and it is possible that the monsoon climate inhibits the temperature effect and shows an anti-temperature effect [30]. The arid area in the northwest is far away from the source of the ocean water vapor, and the geographical conditions are complex. The dynamic fractionation of water vapor 
migration is strong. The precipitation is mostly due to the evaporation of water vapor in different water bodies in the arid inland areas, so the precipitation slope is smaller than the standard value of the global meteoric water line [31-33]. The precipitation isotopes are prone to enrichment by an increasing temperature, and they have significant temperature effects [34]. There is also a certain precipitation effect on the scale of precipitation events [35]. The water vapor in the northwest is mainly driven by the Westerlies and the Asian monsoon, but the source of water vapor is more complicated [3637]. Some studies [38] have found that there were two water vapor paths in the northwest arid area, which were seawater vapor in the Atlantic Ocean and water vapor in the Polar Arctic Ocean region, transported by the Westerlies. As for their influence, their $\delta^{18} \mathrm{O}$ is lower in the cooler part of the year and higher in the warmer part of the year. Based on the above analysis, it can be found that, in China, the stable isotope characteristics of precipitation in the monsoon region are mainly controlled by monsoon intensity or precipitation, while the stable isotopes of precipitation in the non-monsoon region are more affected by the local topography, temperature and precipitation.

The Shiyang River Basin is located in the transitional zone, between the eastern monsoon region, the northwest arid region and the Qinghai-Tibet alpine region. It is located in the monsoon marginal zone, and its water vapor cycle is controlled by the plateau monsoon and westerly circulation. It is also weakly affected by the East Asian summer monsoon [39]. The upper reaches of the Shiyang River originate from the eastern section of the Qilian Mountains, with a complex topography, diverse vegetation resources, varied mountain climates and unique hydrological conditions. Under the influence of the variability and instability of the coupled circulation system and the variability of regional microclimates, precipitation in this area shows complex stable isotopic patterns [40]. In recent years, with the changes in the global climate and regional underlying surface, the water conservation function, precipitation and runoff of the Qilian Mountains have changed [41-43]. The hydrological cycle is becoming more and more complex, which not only threatens the local social economy and the sustainable development of an oasis in the lower reaches of the basin, but it also affects the construction of ecological security barriers in Northwestern China and even the whole country. It is urgent to conduct in-depth research on the complex hydrological processes in the context of global changes. Therefore, this paper takes the Binggou River Basin in the upper reaches of the Shiyang River as a research object and analyzes the stable isotope characteristics of precipitation and their water vapor source so as to provide a theoretical basis for further research on the hydrological process of isotopes in the Qilian Mountains. The study is divided into three parts: (1) the temporal variation of the stable isotopes of precipitation in a watershed; (2) the effects of isotopes in the Binggou
River; and (3) the influence of water vapor sources and atmospheric circulation on the isotopic composition of precipitation in the Binggou River Basin.

\section{Data and Methods}

\section{Study Area}

The Qilian Mountains, located on the northeastern margin of the Qinghai-Tibet Plateau, constitute a natural zone that belongs to the transition zone between the arid northwestern region, the eastern monsoon region and the Qinghai-Tibet Plateau alpine region. This region is dominated by a westerly circulation, plateau monsoon and southeast monsoon, and it is a typical coupling region of atmospheric circulation [40]. The special geographical location makes the geographical environment of this region very complex and sensitive to climate change [44]. The length and height of the Qilian range have created a specific alpine climate, water structure and ecosystem, and dozens of inland rivers - including the Shiyang, Heihe and Shule - have developed. These inland rivers wind from the mountains into the corridor and finally into the vast desert [40, 39].

The Binggou River Basin $\left(37^{\circ} 34^{\prime} 10^{\prime \prime}-37^{\circ} 47^{\prime} 20^{\prime \prime} \mathrm{N}\right.$, $\left.102^{\circ} 11^{\prime} 0^{\prime \prime}-102^{\circ} 31^{\prime} 0^{\prime \prime} \mathrm{E}\right)$ in the study area is an important mountain stream river in the upper reaches of the Shiyang in the eastern sector of the Qilians. It originates from the Chailong Haizi Line of the Zangnan Mountains at the northern foot of the Qilians. The watershed is $45 \mathrm{~km}$ long, and its elevation span is $4095 \mathrm{~m}$. The catchment area is $350 \mathrm{~km}^{2}$. This region is located in the alpine, semi-arid and semi-humid area of the Qilians. According to the local meteorological records from 1953 to 2014, the annual average temperature in this region is $7-10^{\circ} \mathrm{C}$, annual precipitation is $200-700 \mathrm{~mm}$, and annual evaporation is $700-800 \mathrm{~mm}$. Winter is cold and long, summer is hot and short, and the temperature increases quickly in spring and decreases quickly in autumn [45].

\section{Sample Collection and Testing}

A sampling point $(37.891 \mathrm{~N}-102.4182 \mathrm{E}, 2379 \mathrm{~m}$ above sea level) was selected for the collection of precipitation water samples and monitoring meteorological elements, such as precipitation and temperature in Qilian Township in the middle reaches of the Binggou River Basin (Fig. 1 and Table 1).

From September 2016 to August 2017, local meteorological observers were entrusted with the task of collecting precipitation samples. All precipitation samples were collected according to a definition of precipitation events, which was determined by meteorological observation, that is, all precipitation from 20:00 on the same day to 20:00 on the next day was defined as a precipitation event, and a sample was collected. All precipitation samples were collected 


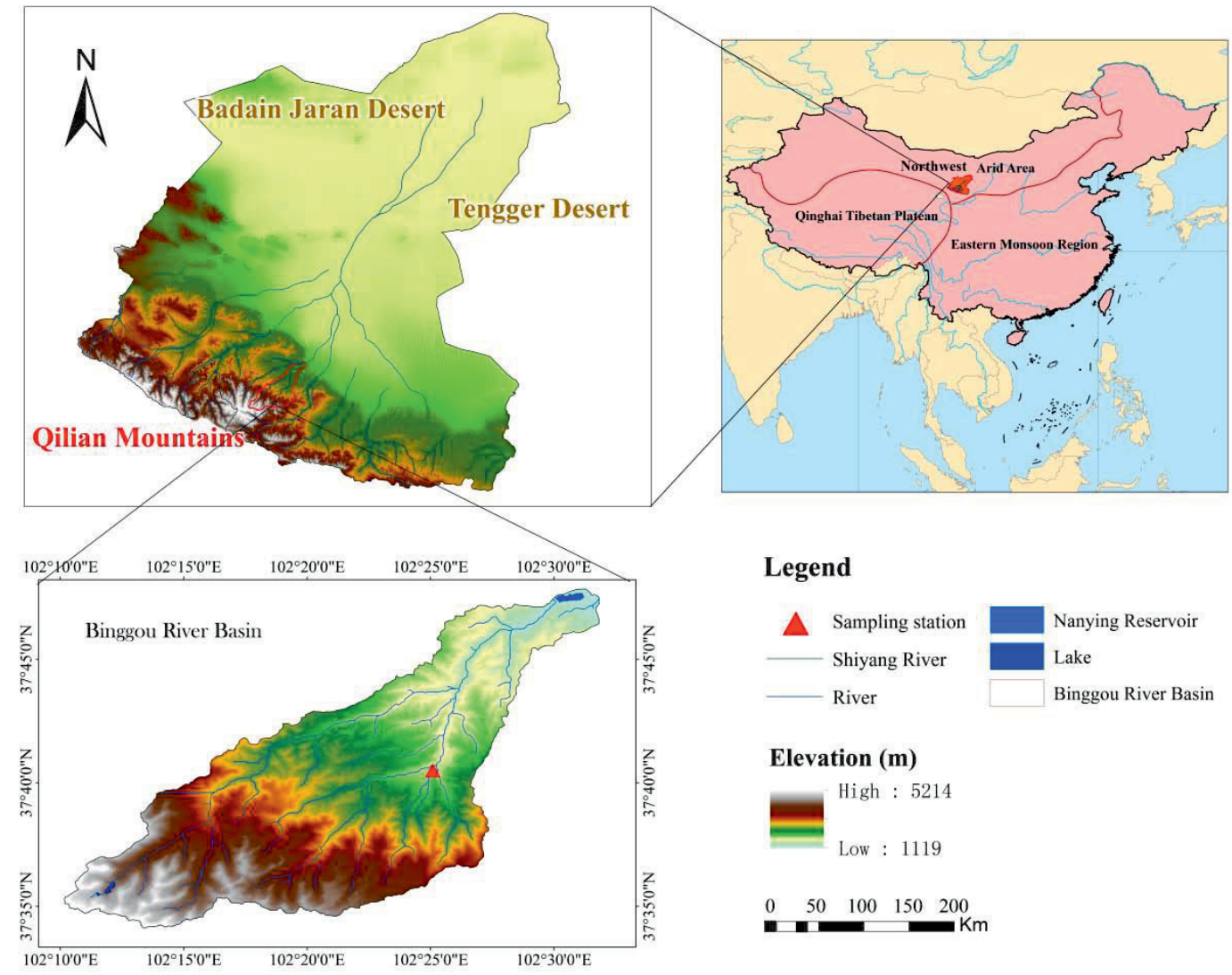

Fig. 1. Locations of the sampling sites.

using a precipitation collector with a $5 \mathrm{~L}$ polyethylene collection bottle (bottom) and a $26 \mathrm{~cm}$ polyethylene funnel. In order to avoid possible contamination of the precipitation samples, all of the sampling equipment was cleaned before sample collection. After each precipitation process, samples of rain (snow) water were collected immediately and packed into $50 \mathrm{ml}$ high-density polyethylene plastic bottles. The mouth of each bottle was sealed with Parafilm plastic film. Snow samples were collected and then packed in selfsealed bags. They were melted at room temperature and transferred to polyethylene bottles. All precipitation samples were stored in cold storage until analysis. During the sampling period, meteorological parameters such as temperature, precipitation, water vapor pressure and relative humidity were recorded by Spectrum Watch Dog 2000.

A hydrogen and oxygen stable isotope test was conducted in the laboratory of Northwest Normal University. All $\delta \mathrm{D}$ and $\delta^{18} \mathrm{O}$ samples were analyzed by a DLT-100 liquid water isotope analyzer from the
Los Gatos Research Company. The analyzer uses offaxis integrated cavity output spectroscopy technology to provide real-time measurement and high-resolution laser absorption spectrum display for testing the isotopic ratio of the water samples, which were filtered by a 0.22 um acetic acid fibre needle filter and injected into a micro bottle, then tested on the apparatus. The standard samples are work samples (LGR3C, LGR4C, LGR5C), provided by the LGR company in accordance with the V-SMOW (Vienna Standard Mean Oceanic Water) configuration. Each water sample and isotope standard sample were injected six times in a row. In order to avoid the memory effect of isotope analysis, the first two injections were discarded, and the last four average values were used as measurements. All test results are expressed by the micrometer difference, relative to V-SMOW:

$$
\delta^{18} \mathrm{O}(\delta \mathrm{D})=\left(\frac{R_{\mathrm{S}}}{R_{\mathrm{V}-\mathrm{SMOW}}}-1\right) \times 1000 \% \text { o }
$$

Table 1. Locations of sampling stations and associated isotopic composition

\begin{tabular}{|c|c|c|c|c|c|c|c|c|c|}
\hline Station & $\begin{array}{c}\text { Longitude } \\
\left({ }^{\circ} \mathrm{E}\right)\end{array}$ & $\begin{array}{c}\text { Latitude } \\
\left({ }^{\circ} \mathrm{N}\right)\end{array}$ & $\begin{array}{c}\text { Elevation } \\
(\mathrm{m})\end{array}$ & Samples & $\begin{array}{c}\text { Ann-ave- } \\
\text { Temperature } \\
\left({ }^{\circ} \mathrm{C}\right)\end{array}$ & $\begin{array}{c}\text { Ann-ave- } \\
\text { Precipitation } \\
(\mathrm{mm})\end{array}$ & $\begin{array}{c}\text { Ave- } \boldsymbol{\delta} \mathrm{D} \\
(\% \mathbf{0})\end{array}$ & $\begin{array}{c}\text { Ave- } \boldsymbol{\delta}^{18} \mathrm{O} \\
(\%)\end{array}$ & $\begin{array}{c}\text { Ave- } d \text {-excess } \\
(\%)\end{array}$ \\
\hline Qilin township & 37.891 & 102.418 & 2379 & 35 & 7.469 & 442 & -52.212 & -7.944 & 11.295 \\
\hline
\end{tabular}


...where $R_{\mathrm{S}}$ and $R_{\mathrm{V}-\mathrm{Smow}}$ are the ratio of $\mathrm{D} / \mathrm{H}$ or ${ }^{18} \mathrm{O} /{ }^{16} \mathrm{O}$ in the water samples and V-SMOW, respectively. The accuracy of the test was as follows: $\delta^{18} \mathrm{O} \pm 0.1, \delta \mathrm{D} \pm 0.5 \%$.

The isotope Rayleigh fractionation model:

$$
\delta_{\text {precipitation }}=\left(f^{\partial-1}-1\right) \times 1000
$$

In formula (2), $-\delta_{\text {precipitation }}$ is the hydrogen and oxygen isotopes of precipitation, $f$ is the percentage of the residual vapor in a cloud cluster, and $\partial$ is the fractionation coefficient of precipitation at condensation temperature, and $\partial>1$ at room temperature.

The reconstruction of the backward trajectory of the air mass reaching the sampling point is based on the Hybrid Single Particle Lagrangian Integrated Trajectory (HYSPLIT) model of the National Oceanic and Atmospheric Administration Air Resources Laboratory of the United States, which is a professional meteorological model for calculating and analyzing the trajectory of atmospheric pollutant transport and diffusion [46-47]. The reanalysis data used in the operation of the model are from the Global Data Assimilation System (GDAS) of the National Center for Environmental Forecasting/National Center for Atmospheric Research of the United States. The spatial resolution of the reanalysis data is $2.5^{\circ} \times 2.5^{\circ}$, with 17 vertical layers.

The clustering analysis algorithm in the backward trajectory tracking of the HYSPLIT model considers multiple trajectories, according to the principle that the trajectory path is at its closest. The model adopts the overall spatial minimum variance clustering analysis method, proposed by Draxler et al. [47]. The clustering criterion is that the spatial variance (SV) of each class is the square of the distance between each trajectory of the class and the average trajectory of the class. Additionally, total spatial variance (TSV) is the sum of the variances of the various types. The corresponding class classification is the final result, when the total variance increases its minimum.

The principle of the channel contribution rate of the water vapor movement track in different geographical directions is calculated by the trajectory model [48]:

$$
Q_{S}=\frac{\sum_{1}^{m} q_{\text {last }}}{\sum_{1}^{n} q_{\text {last }}} \times 100 \%
$$

...where $Q_{S}$ represents the moisture contribution rate of the channels in different geographical directions; $q_{\text {last }}$ represents the specific humidity of the final position in the channel; $m$ represents the number of tracks contained in the channel; and $n$ is the total number of trajectories.

The relationship among the isotope compositions was evaluated by the linear regression method, and the correlation between the meteorological parameters and isotopes was tested by the Pearson and Spirson methods. All statistical analyses were carried out in SPSS.24.0.

\section{Results and Analysis}

\section{Distribution Characteristics of the Meteoric Water Line and Precipitation $\left(\delta \mathrm{D}\right.$ and $\left.\delta^{18} \mathrm{O}\right)$}

The meteoric water line can better reflect the physical geography and meteorological conditions of a region and aid in the analysis of historical climate changes and water vapor sources [49]. The slope of the meteoric water line is mainly affected by the average temperature in the cloud cluster, when the raindrops condense. When precipitation occurs as the temperature drops, the isotope composition of the rainwater is controlled by the equilibrium fractionation between the water and vapor. The slopes of these points on the meteoric water line are close to 8 [50]. Because of the difference in the geographical environment and climate, the slope and intercept of the meteoric water line are different in different regions, and these differences also reflect the difference of the source, condensation and transportation process of the meteoric water vapor in different regions [51].

The stable isotope data of all precipitation events in the Binggou River Basin are regressed and analyzed to obtain the local meteoric water line (LMWL) of the whole study area. As shown in Fig. 2, there is a good correlation between $\delta \mathrm{D}$ and $\delta^{18} \mathrm{O}$ over the whole year: $\delta \mathrm{D}=5.248-10.522$, and $\mathrm{R}^{2}=0.797$. Compared with the global meteoric water line (GLWL: $\left.\delta \mathrm{D}=8 \delta^{18} \mathrm{O}+10\right)[46]$ and the meteoric water line in northwest China [52] $\left(\delta \mathrm{D}=7.05 \delta^{18} \mathrm{O}-2.17\right)$, its slope and intercept are obviously low. This indicates that the water vapor of the precipitation in this area comes from the source with different stable oxygen isotope ratios. In addition, raindrops fall to the ground and experience a degree of secondary evaporation under the influence of the dry atmosphere $[1,53]$, and isotope unbalanced fractionation occurred, which eventually led to a smaller slope of the meteoric water line [3].

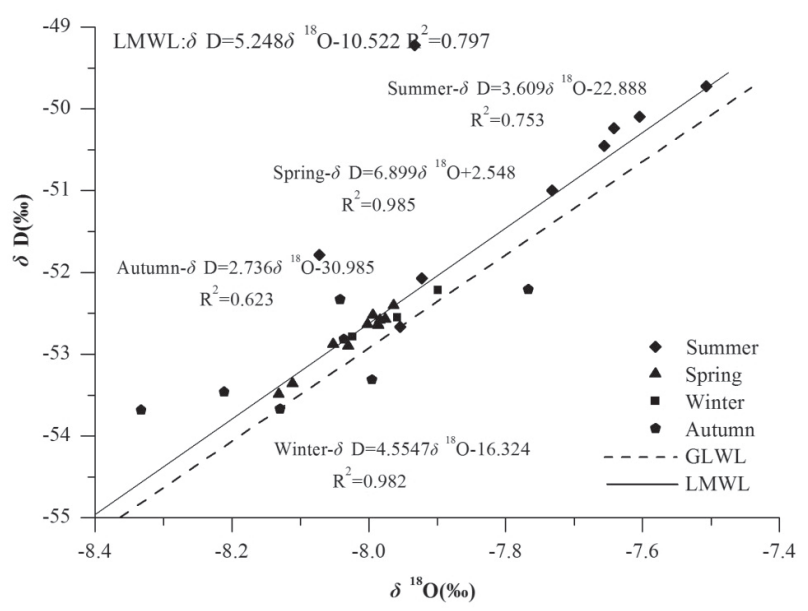

Fig. 2. Relationship between $\delta \mathrm{D}$ and $\delta^{18} \mathrm{O}$ in precipitation in the Binggou River Basin. 
The slope and intercept of the small meteoric water line in the Binggou River Basin are consistent with the characteristics of an arid area [32, 38].

The distribution of the isotope values of $\delta \mathrm{D}$ and $\delta^{18} \mathrm{O}$ is different in different seasons (Fig. 2). The variation range of the isotope values of $\delta \mathrm{D}$ and $\delta^{18} \mathrm{O}$ is small in winter and spring, and they are concentrated at the precipitation line and in its vicinity. The correlation coefficients are all above 0.9 , which means a good linear relationship between them. The slope and intercept of the Meteoric Water Line in summer and autumn are obviously lower than they are in winter and spring. The distribution of the values of $\delta \mathrm{D}$ and $\delta^{18} \mathrm{O}$ is quite scattered, and the deviation degree between some sample points and the meteoric water line is large, which shows that there is an obvious unbalanced fractionation in summer and autumn. Variable local climatic conditions, different forms of precipitation and complex water vapor sources may cause seasonal differences in the atmospheric precipitation lines in this study area [1].

\section{Temporal Variation Characteristics of the Stable Isotopes of Precipitation}

During the sampling period, the stable isotope values of all precipitation events changed over time, as shown in Fig. 3. The variation ranges of the precipitation $\left(\delta^{18} \mathrm{O}\right.$ and $\left.\delta \mathrm{D}\right)$ values in the study area are -8.333 to $-7.506 \%$ and -53.683 to $-49.223 \%$, and the average values are $-7.944 \%$ and $-52.212 \%$, respectively. $d$-excess ranges between $9.928-14.387 \%$, and the average value is $11.343 \%$. The isotopic values fall within the stable isotopic composition range $\left(\delta^{18} \mathrm{O}\right.$ : $10-50 \%$; $\delta \mathrm{D}: 50-350 \%$ ) [4] of global precipitation.

The change trends of the values of $\delta^{18} \mathrm{O}$ and $\delta \mathrm{D}$ are basically the same, which shows a gradual decline from August to November and a fluctuating upward trend from November to August. There is a sharp fluctuation in summer and autumn and a steady fluctuation in winter and spring. On the whole, the isotopic value was generally high in summer and low in winter.

The higher isotope values in summer in the study area are consistent with the results concerning isotope enrichment in warm season precipitation in arid and semi-arid regions all over the world $[52,3]$.

The deuterium surplus parameter ( $d$-excess = $\left.\delta \mathrm{D}-8 \delta^{18} \mathrm{O}\right)$, also known as the deuterium excess parameter, refers to the variation of the parallel fractionation between $\delta \mathrm{D}$ and $\delta^{18} \mathrm{O}$ caused by a dynamic fractionation of precipitation in the evaporation process, resulting in a difference that is mainly controlled by the temperature, wind speed and relative humidity of the water vapor source [54]. The $d$-excess values are between $10.328-12.979 \%$, with an average value of $11.295 \%$, in the study area. In terms of temporal variation (Fig. 3 right), the $d$-excess value decreased gradually from October to February of the following year and then increased sharply. The fluctuation decreased from March to June and then increased gradually. The high value of $d$-excess mainly appeared in November and March, while the low value mainly appeared in February and from June to July. In general, there is a negative correlation between the $d$-excess value and temperature. The main reason for this phenomenon is that the higher temperature in summer increases the secondary evaporation of rain in the process of falling, leading to a significant decrease in the $d$-excess value. While evaporation is weak in winter, the air is dry and there is very little precipitation. In the process of precipitation, rain drops are condensed by evaporation through dry air, leading to the occurrence of a low $d$-excess value. In August, with the increase of the relative humidity in the atmosphere, the $d$-excess value also increases. In summer, the partial precipitation shows a trend of a negative $\delta^{18} \mathrm{O}$, with a higher $d$-excess value, and this may be affected by the local water vapor recycling or monsoon water vapor, generated by strong evaporation.
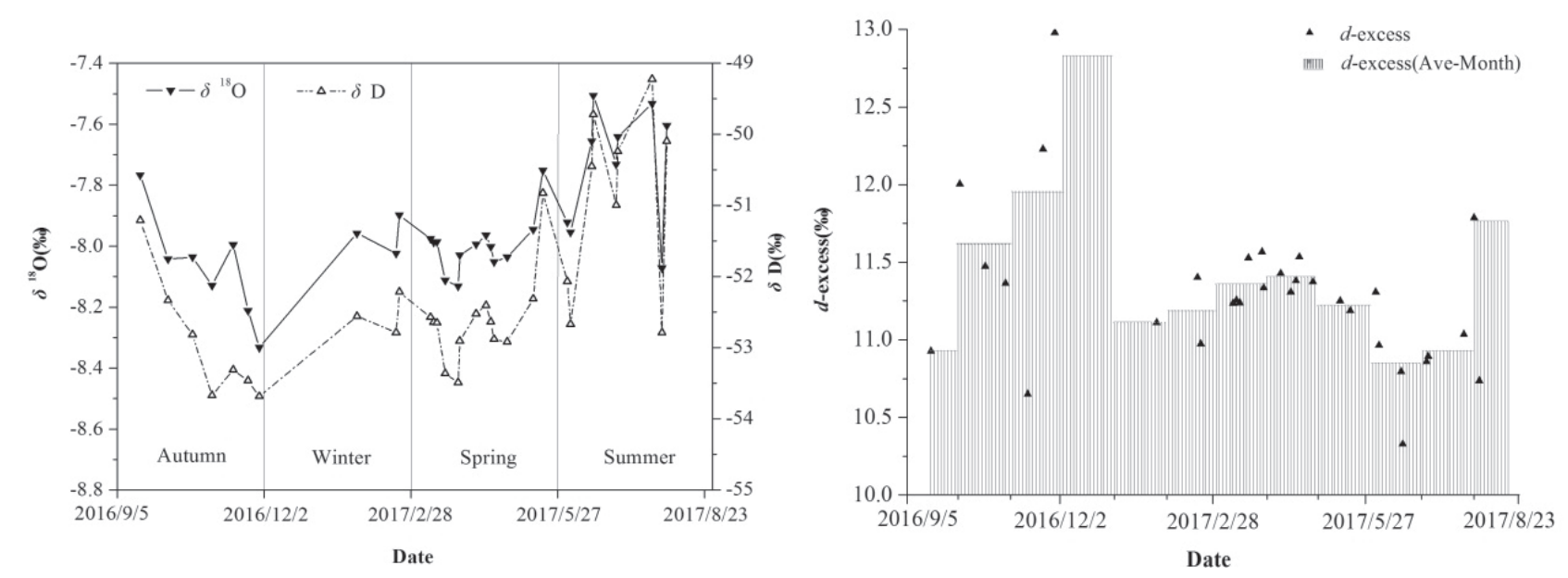

Fig. 3. Temporal variation of $\left(\delta^{18} \mathrm{O}, \delta \mathrm{D}\right)$ and $d$-excess in precipitation at the Binggou River Basin. 

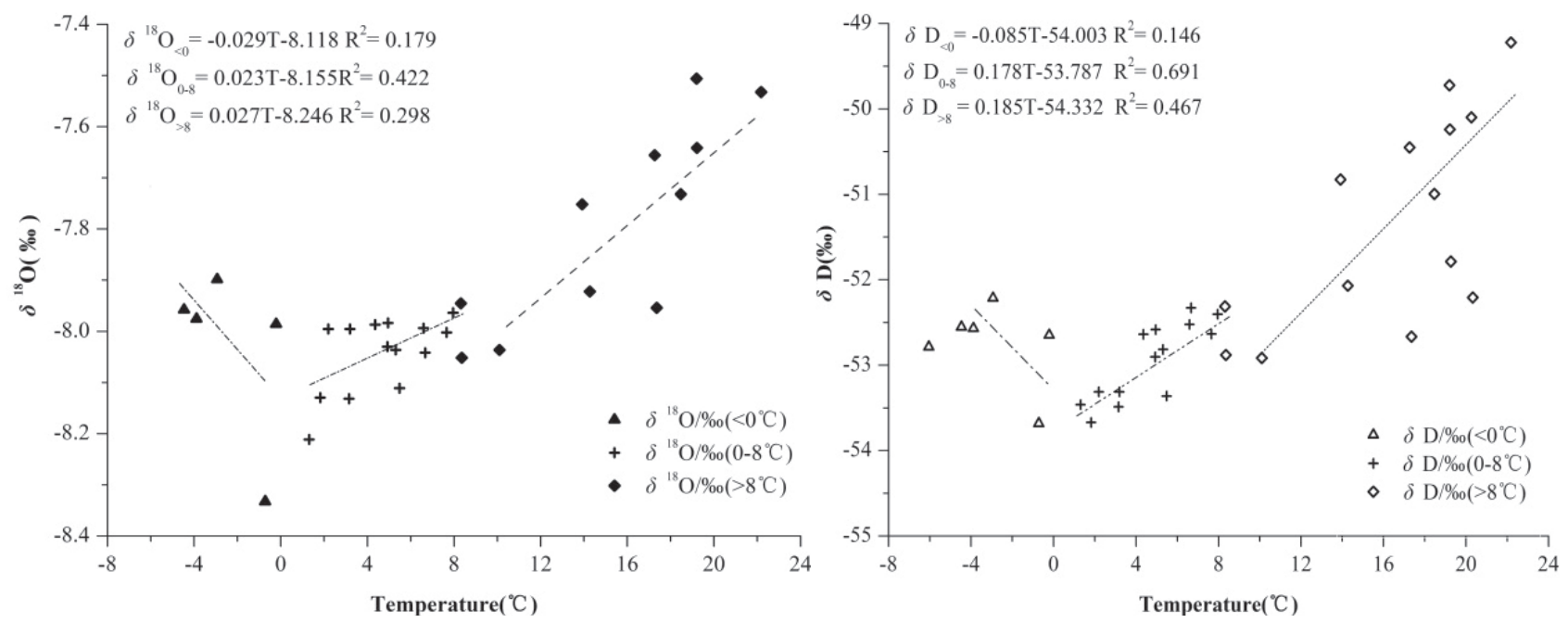

Fig. 4. Relationship between temperature and $\delta^{18} \mathrm{O}$ and $\delta \mathrm{D}$ in the Binggou River Basin.

\section{Environmental Isotope Effect}

\section{The Relationship between the Stable Isotopes of Precipitation and Temperature}

Generally speaking, temperature is an important factor affecting the variation of the stable isotopes of precipitation. This is because the fractionation of environmental isotopes is mainly controlled by the temperature in the process of phase transformation [30]. A temperature effect means that there is a significant positive correlation between the stable isotopes of precipitation and temperature.

Fig. 4 divides the precipitation samples into three groups based on the temperature changes. The first group is temperature $<0^{\circ} \mathrm{C}$. There is inconspicuous negative correlation between the $\delta^{18} \mathrm{O}$ and $\delta \mathrm{D}$ of the precipitation events and the temperature (which failed the 0.05 significance level test). In the second group, the temperature ranged from 0 to $8^{\circ} \mathrm{C}$, and the precipitation was steady in terms of $\delta^{18} \mathrm{O}$ and $\delta \mathrm{D}$. The stable isotope values showed a significant positive correlation with the temperature. According to the Rayleigh fractionation model of a precipitation isotope (Formula 2), the lower the condensation temperature of precipitation clouds, the larger the fractionation coefficient and the smaller the isotope value of precipitation. Only when the isotope value of the water vapor in the atmosphere remains basically stable is it possible to show a positive correlation with the temperature. In the third group, when the temperature is higher than $8^{\circ} \mathrm{C}$, the precipitation at $\delta^{18} \mathrm{O}$ and $\delta \mathrm{D}$ are positively correlated with the temperature, while $\delta \mathrm{D}$ is stable temperature. This is because the two factors, i.e., the enrichment of the stable isotope value caused by the temperature effect and the dilution of the stable isotope value caused by water vapor recycling, contribute to the relatively stable state of the internal cycle [26, 39].

The above analysis shows that the stable isotope temperature effect of precipitation in the Binggou River Basin is obvious under a temperature condition of above $0^{\circ} \mathrm{C}$, showing the characteristics of arid regions, while under a condition of below $0^{\circ} \mathrm{C}$ it shows a weak antitemperature effect, which is consistent with the antitemperature effect of the stable isotopes of precipitation in the southeastern monsoon region of China. Therefore, the relationship between the stable isotopes of precipitation and temperature in the Binggou River Basin shows the transition from the eastern monsoon region to the northwest arid region.

\section{The Relationship between the Stable Isotopes of Precipitation and the Amount of Precipitation}

A rainfall effect means that the change in the composition of the isotopes of precipitation is mainly affected by rainfall, that is, the more rainfall there is,

Table 2. Correlation between temperature and $\delta^{18} \mathrm{O}$ and $\delta \mathrm{D}$ at different temperature ranges in Qilian Township of the Binggou River Basin.

\begin{tabular}{|c|c|c|c|c|}
\hline & $\begin{array}{c}\text { Temperature effect } \\
\left(\%{ }^{\circ} \mathrm{C}^{-1}\right)\left(\mathrm{R}^{2}\right)\end{array}$ & $\begin{array}{c}\text { Temperature effect below } \\
0^{\circ} \mathrm{C}\left(\%{ }^{\circ} . \mathrm{C}^{-1}\right)\left(\mathrm{R}^{2}\right)\end{array}$ & $\begin{array}{c}\text { Temperature effect at } \\
0-8^{\circ} \mathrm{C}\left(\%{ }^{\circ} . \mathrm{C}^{-1}\right)\left(\mathrm{R}^{2}\right)\end{array}$ & $\begin{array}{c}\text { Temperature effect above } \\
8^{\circ} \mathrm{C}\left(\% 0 .{ }^{\circ} \mathrm{C}^{-1}\right)\left(\mathrm{R}^{2}\right)\end{array}$ \\
\hline$\delta^{18} \mathrm{O}$ & $0.015(0.408)^{* *}$ & $-0.029(0.179)$ & $0.023(0.422)^{* *}$ & $0.027(0.298)$ \\
\hline$\delta \mathrm{D}$ & $0.104(0.546)^{* *}$ & $-0.085(0.146)$ & $0.178(0.691)^{* *}$ & $0.185(0.467)^{*}$ \\
\hline
\end{tabular}

* indicates that it passed the 0.05 confidence test; ** indicates that it passed the 0.01 confidence test. 

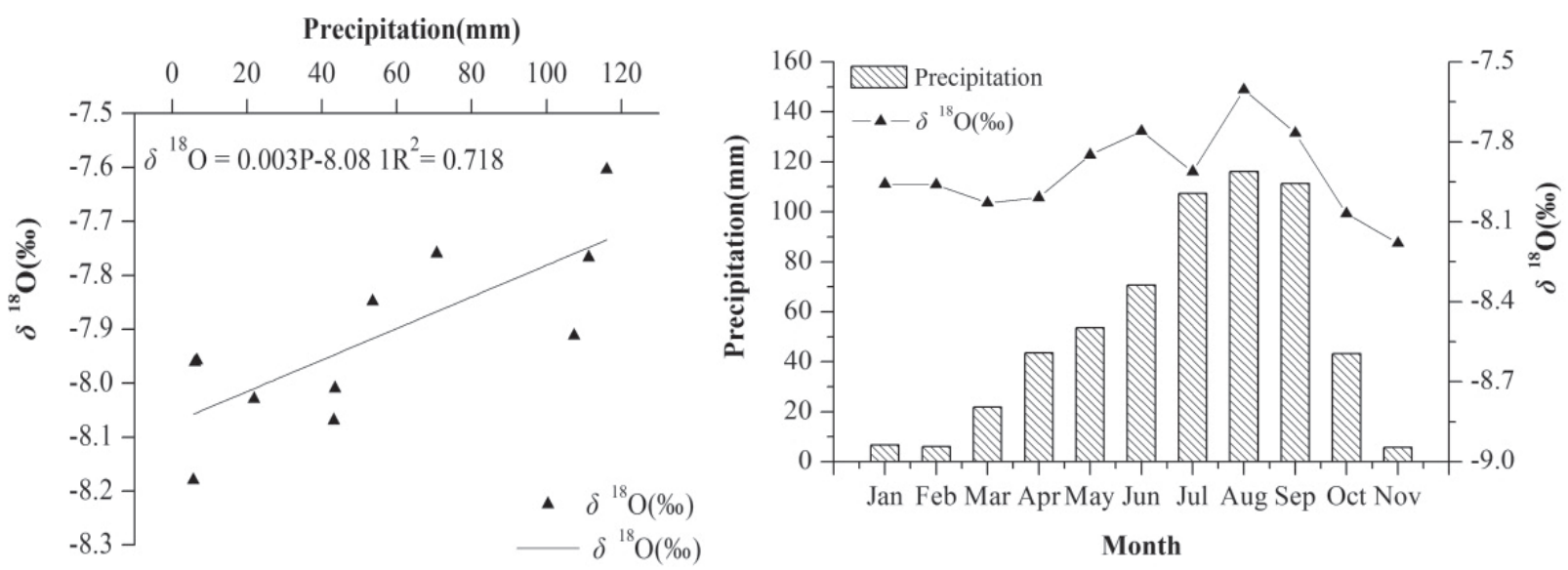

Fig. 5. Relationship between $\delta^{18} \mathrm{O}$ and precipitation.

the more negative the composition of the isotopes of precipitation will be $[1,55]$. Over the whole year, there is a positive correlation between the monthly mean value of precipitation $\left(\delta^{18} \mathrm{O}\right)$ and monthly precipitation (Fig. $5, \mathrm{R}^{2}=0.718$ ) in the Binggou River Basin. The isotope value of precipitation is not depleted by the increase of precipitation, which indicates that the precipitation effect is not reflected in the monthly time scale.

The warm season (June-September), with more precipitation, is also the season with a higher temperature in the Binggou River Basin, with hot and rainy periods. The dynamic fractionation of precipitation is dominant in the process of condensation. A certain amount of local recycling water vapor may be mixed in the process of raindrops falling. The obvious temperature effect masks the precipitation effect to a certain extent. The relationship between the precipitation isotope $\left(\delta^{18} \mathrm{O}\right)$ and the amount of precipitation in the Binggou River Basin has a certain degree of similarity with the central Hexi Corridor [3]. In fact, the temperature effect masks the precipitation effect, which makes the precipitation effect impossible to determine.

\section{Discussion}

\section{Water Vapor Source Contribution Ratio}

In order to verify and discuss the influence of water vapor sources on the stable isotope composition of precipitation in the Binggou River Basin, global reanalysis data from 2016 to 2017 were selected, and the annual water vapor source trajectory was simulated using the HYSPLIT 4.9 model in the study area. Taking the sample point in Qilian Township (102.418E, $37.891 \mathrm{~N}$ ) as the end point of the track, back tracing was conducted for $240 \mathrm{~h}$. The elevation of the Binggou River Basin is 1119-5214 m. In addition, previous studies show that maximum water vapor transport occurs in the vicinity of $2000 \mathrm{~m}$ above the ground in China [56]. Therefore, the parameter values of air mass height in this study are $1500 \mathrm{~m}, 2000 \mathrm{~m}$ and $2500 \mathrm{~m}$ above the ground. Firstly, all precipitation events from September 2016 to August 2017 are analyzed day-byday, then the cluster analysis method is used to cluster the airflow trajectories of spring (March-May) and summer (June-August), autumn (September-November) and winter (December-February of the next year), and the proportions of each transportation path in the four seasons is calculated according to the clustering results.

The water vapor source paths of all precipitation events that occurred in the study area are clustered, the numbers shown in Table 3 represent the percentage of water vapor from four different sources in all seasons. There are significant differences in the water vapor sources in different seasons. In winter, the nearsurface westerlies move southward with the southward shift of the direct sun point, and the control of the westerly circulation to the northwest and northeast and in Northern China is strengthened. The water vapor carried by the westerly wind contributes the most to

Table 3. Statistical table of the percentage of water vapor sources.

\begin{tabular}{|c|c|c|c|c|}
\hline Source & Spring & Summer & Autumn & Winter \\
\hline Westerly & 55 & 47 & 51 & 61 \\
\hline Inland & 18 & 24 & 41 & 36 \\
\hline South & 0 & 14 & 0 & 0 \\
\hline North & 27 & 15 & 8 & 3 \\
\hline
\end{tabular}


the precipitation in the Binggou River Basin, reaching $61 \%$. However, the inland re-evaporation of water vapor (mostly from the evaporation near the study area, formed in Xinjiang, Tibet, Qinghai, Mongolia and other places) and their contribution is $36 \%$. The water vapor from the north (northern water vapor is from in the southern margin of the Arctic Ocean, Greenland and Siberia, Russia, etc.) is only $3 \%$. In the summer, the westerlies moves northward, with a northward shift of the direct sun point. Its control over northern China is weakened, and the influence of the summer monsoon is gradually enhanced. Therefore, the proportion of westerly water vapor from the water vapor sources of precipitation in the Binggou River Basin, which is located at the edge of the monsoon region, decreased by $47 \%$. The proportion of ocean water vapor from the southwest and southeast monsoon increased by $14 \%$, and that from inland and the north was $24 \%$ and $15 \%$, respectively. In the transition season between winter and summer, i.e., in spring and autumn, the westerly circulation, monsoon circulation and local circulation system are extremely unstable, which makes the composition of precipitation water vapor sources in the Binggou River Basin more complex, but the influence of the westerly circulation water vapor on the two seasons is basically the same, at $55 \%$ and $51 \%$, respectively. The differences are as follows: in spring, the westerlies move northward, and the Siberian High does not disappear completely in the process of westward movement and recession. Therefore, the influence of water vapor from the north on its precipitation is higher, accounting for $27 \%$, while the influence of inland re-evaporation water vapor on its precipitation is only $18 \%$. In autumn, the westerly belt moves southward, and the Siberian High has not really formed. Therefore, the influence of the westerly circulation water vapor on its precipitation is still dominant, accounting for $51 \%$, followed by the inland water vapor, accounting for $41 \%$. Therefore, from the source of precipitation and water vapor, the Binggou River Basin has the characteristics of

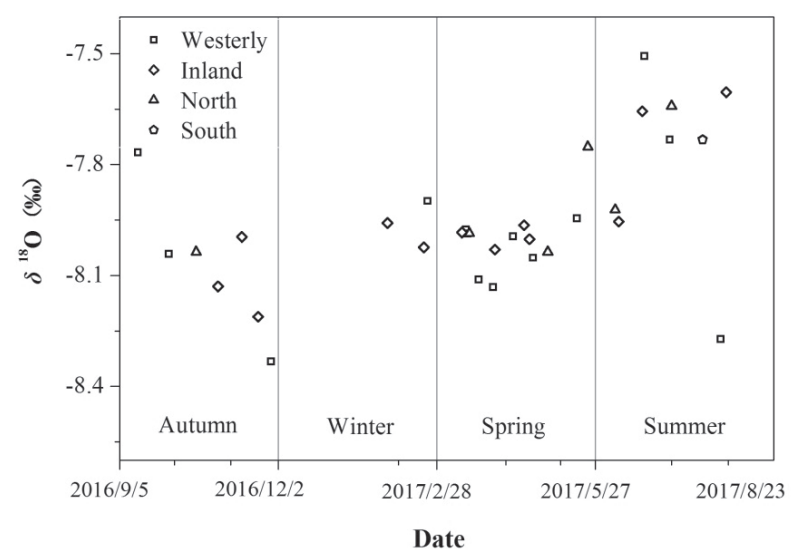

Fig. 6. Distribution map of $\delta^{18} \mathrm{O}$ value in precipitation formed by water vapor from different sources of all precipitation events in the Binggou River Basin. a transitionary area between the eastern monsoon region and the northwest arid region.

\section{Sources of Water Vapor and Stable Isotopes}

The corresponding relationship between the water vapor source of precipitation events and the value of precipitation $\left(\delta^{18} \mathrm{O}\right)$ is shown in Fig. 6. It can be found that, even with the same water vapor source, the stable isotope values of precipitation produced in different seasons are quite different. Considering spring and summer, where precipitation events frequently occur, the relationship between the water vapor sources and stable isotope values of typical precipitation events and their influencing factors are analyzed.

The sources of water vapor in summer are complex, and all kinds of water vapor contribute a certain proportion to the precipitation of the Binggou River Basin (Table 3). The precipitation events that occurred on August 4 were represented by three different sources of water vapor (Fig. 7a), which were southwestern Mongolia $(1500 \mathrm{~m})$ and western Russia $(2000 \mathrm{~m}$ and $2500 \mathrm{~m}$ ), both of which were land-based sources of water vapor. In addition, they were supplemented by a large amount of inland re-evaporation water vapor during their transportation to the study area, resulting in a higher value of precipitation $\left(\delta^{18} \mathrm{O}\right)$. Fig. $\left.7 \mathrm{~b}\right)$ shows that the water vapor of the precipitation events on July 22 mainly originated from the South China Sea $(1500 \mathrm{~m}$ and $2000 \mathrm{~m})$, which indicates that the water vapor transport in the Binggou River Basin cannot be ignored in relation to the summer monsoon. While the study area is deeply inland and located at the edge of the monsoon region, when the westerly wind weakens and the monsoon strengthens, some southwest and southeast monsoon water vapor will arrive. The stable isotope value of precipitation caused by this part of the water vapor is generally low. However, the source water vapor arriving at the study area from the sea will certainly cause lower isotope values. For example, the source water vapor of the precipitation event on 5 July originated from the Barents Sea $(1500 \mathrm{~m})$, the Hexi Corridor $(2000 \mathrm{~m})$ and the Norwegian Sea $(2500 \mathrm{~m})$. The lower value of $\delta^{18} \mathrm{O}$ of the ocean water vapor does not match the higher value of precipitation in this precipitation event (Fig. 7c). This is because the oceanic vapor carried by the westerly wind circulation and polar circulation is almost exhausted in the process of being transported to the study area, which is accompanied by the evaporation of water vapor on the land surface due to the higher temperature along the way. Therefore, the circulation system originating from the ocean undergoes denaturation, when it reaches the edge of the monsoon region, and it has obvious land-origin characteristics. At the same time, the high temperature inside the continent during the summer makes the raindrops experience a certain degree of secondary evaporation during the landing process, 

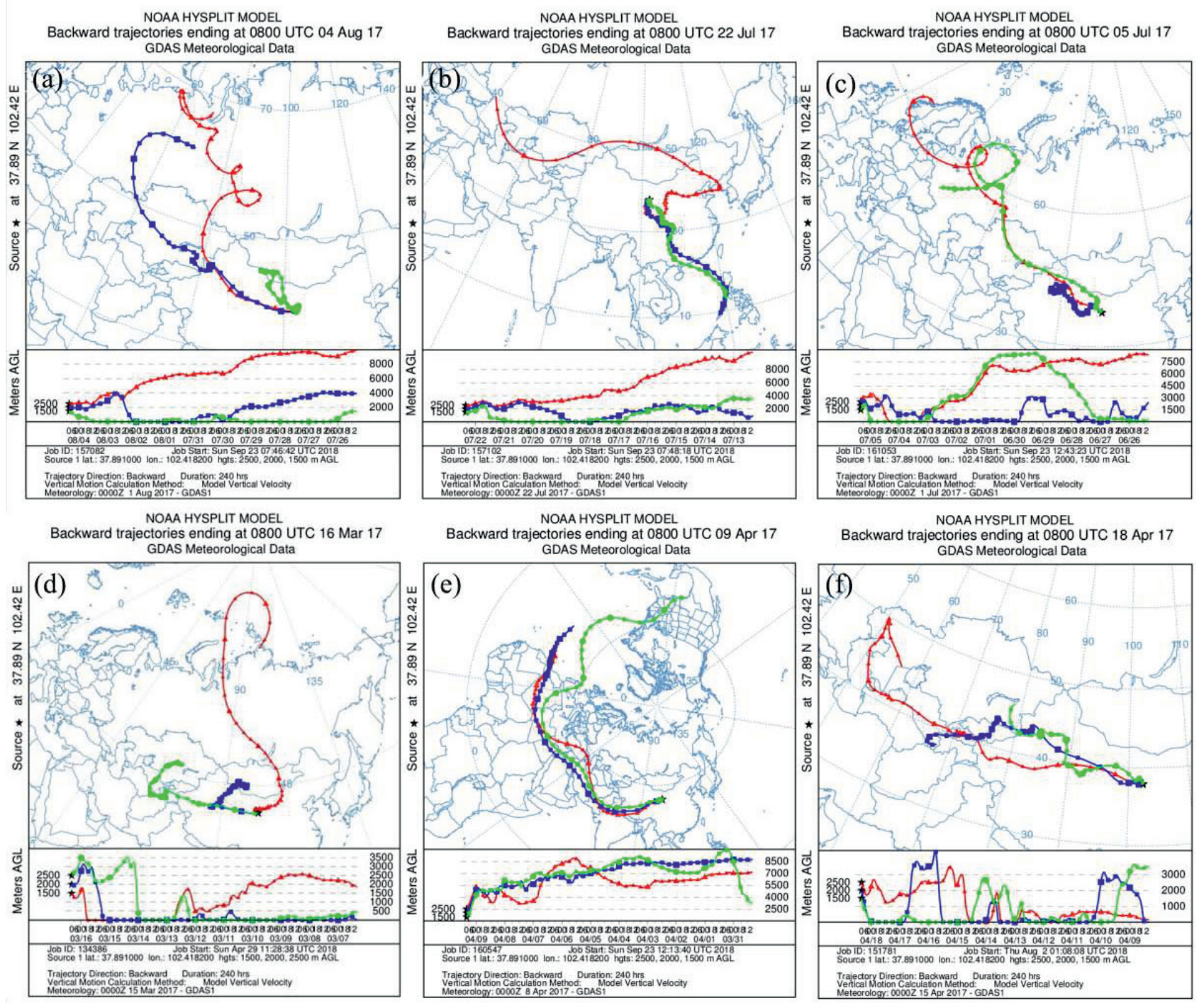

Fig. 7. Example of water vapor tracing path for typical precipitation events in spring and summer.

* Note: green represents the height of backtrack is $1500 \mathrm{~m}$, blue is the height of backtrack is $2000 \mathrm{~m}$, and red is the height of $2500 \mathrm{~m}$ backtracking.

resulting in a higher $\delta^{18} \mathrm{O}$ value of this precipitation event.

The precipitation events on March 16 and April 9 were influenced by westerly circulation and winter monsoon circulation (Figs 7a and 7b). The precipitation events on April 18 (Fig. 7c) were mainly controlled by the westerly wind. The sources of water vapor were Lake Balkash $(1500 \mathrm{~m})$, Central Asia $(2000 \mathrm{~m})$ and the Caspian Sea $(2500 \mathrm{~m})$, respectively. Considering the water vapor originating from ocean and land lakes, the $\delta^{18} \mathrm{O}$ value in the air mass is continuously lowered in the long-distance transport process through precipitation along the way, and this is coupled with a lower temperature in spring and small land surface evaporation. Therefore, while the water vapor transport distance is relatively long, it still has obvious oceanic properties, resulting in a lower $\delta^{18} \mathrm{O}$ value of precipitation for the three precipitation events.
The above analysis shows that the circulation systems controlling precipitation in the different seasons are obviously different for the Binggou River Basin, which is located inland and at the edge of the monsoon region. Even under the same circulation system, the influence of water vapor from oceans and lakes on the stable isotopes of precipitation is different in different seasons, showing an obvious seasonal effect.

\section{Conclusions}

The slope and intercept of the meteoric water line in the Binggou River Basin are significantly lower than the global meteoric water line and slightly lower than the meteoric water line in northwest China, and the slope and intercept of the meteoric water line in summer and autumn are obviously lower than they are in winter and spring. The $\delta^{18} \mathrm{O}$ of precipitation is enriched in 
the warm season, with an obvious temperature effect (greater than $0^{\circ} \mathrm{C}$ ) and anti-temperature effect (less than $0^{\circ} \mathrm{C}$ ). Variable local climatic conditions, different precipitation patterns and complex water vapor sources may cause seasonal differences to the meteoric water line in the study area. On a monthly scale, the temperature effect masks the precipitation effect, which makes the precipitation effect impossible to determine.

Complex water vapor sources and a special geographic location are the main factors affecting the great seasonal variation of the precipitation values of $\delta^{18} \mathrm{O}$ and $\delta \mathrm{D}$ in the Binggou River Basin. The circulation systems that control the sources of the precipitation water vapor in different seasons are quite different. Among them, the westerly circulation has the greatest influence on the precipitation in the Binggou River Basin, with an average proportion of $53 \%$ for the four seasons. Summer precipitation water vapor sources are the most complex. Among them, the monsoon circulation originating from the southwest and southeast accounts for $14 \%$. However, the study area is deeply inland and located at the monsoon fringe, and the water vapor carried by the circulation from the ocean and lake has an obvious continental nature when it reaches the Binggou River Basin in summer. In other seasons, the moisture that also originates from the ocean during the transportation process is due to the lower land surface temperature along the way, and there is less water vapor from evaporation and replenishment on the land, which still retains an obvious sea source property and shows an obvious seasonal effect when arriving at the research area. Our findings show that the Binggou River Basin, located at the edge of the monsoon region, the characteristics of the seasonal fluctuation of the stable isotopes of precipitation and summer enrichment are similar to those in northwest arid areas. However, the complex water vapor supply source and the relationship between the stable isotopes of precipitation and the temperature show the characteristics of transition from the eastern monsoon region to the arid area of northwest China.

Some preliminary conclusions can be drawn by analyzing the isotopic characteristics, the meteoric water line and water vapor sources of precipitation in this basin. However, there are still some areas of this study that need to be strengthened. First, since the data collection cycle is short, to analyze the inter-annual variation of precipitation, a precipitation isotope study is a long-term and arduous task, and it is necessary to strengthen the study in terms of the time scale in order to obtain scientifically reliable experimental data. The short-term monitoring process of the water circulation mode of interpretation used in the study area is not complete, so this work needs to be further strengthened in the future. Secondly, the current research on isotopes in the basin is only focused on a single water body, and few studies have been conducted on a combination of isotopes with other water bodies in the whole water circulation system. In the future, we will conduct more comprehensive studies, combining atmospheric precipitation, surface water and groundwater, which will be conducive to accurately revealing the special hydrological cycle within this basin.

\section{Acknowledgements}

This research was financially supported by the National Natural Science Foundation of China (41761047, 41661005, 41261104, and 41661084) and the National Natural Science Foundation innovation research group of the science foundation of China (41421061). We are grateful to Xiuting Xu, Yan Wen, Juan Xiang and Xinggang Ma for their assistance in data sampling and laboratory work. We also thank the anonymous referees for their helpful comments on the manuscript.

\section{Conflict of Interest}

The authors declare no conflict of interest.

\section{References}

1. DANDGAARD W. Stable isotope in precipitation. Tellus. 14, 1964.

2. GU W.Z. Isotope Hydrology[M]. Science press.Beijing. P105. 2011.

3. LI J.F., SHI P.J., ZHU G.F., HE Y.Q., LIU Y.F., TONG H.L., YANG L. Characteristics of $\delta^{18} \mathrm{O}$ in precipitation and moisture transports in the central Hexi Corridor.Acta Scientiae Circumstantiae. 35, 4, 2015.

4. ARAGUÁS-ARAGUÁS L., FROEHLICH K., ROZANSKI $\mathrm{K}$. Stable isotope composition of precipitation over southeast Asia . J. Geophys. Res. 103, 1998.

5. AGGARWAL P.K. ROMATSCHKE U., ARAGUASARAGUAS L., BELACHEW D., LONGSTAFFE F.J., BERG P., SCHUMACHER C., FUNK A. Proportions of convective and strati form precipitation revealed in water isotope ratios. Nat. Geosci. 9, 8, 2016.

6. PUTMAN A.L., FENG X., SONDER L.J., POSMENTIER E.S. Annual variation in event-scale precipitation $\delta^{2} \mathrm{H}$ at Barrow, AK, reflects vapor source region. Atmos. Chem. Phys. 17, 2017.

7. MADONIA P., FEDERICO C., FAVARA R. Isotopic composition of rain- and groundwater at Mt. Vesuvius: environmental and volcanological implications. Environ. Earth Sci. 72, 2014.

8. OKAZAKI A., SATOH Y., TREMOY G., VIMEUXET F., SCHEEPMAKER R., YOSHIMURA K. Interannual variability of isotopic composition in water vapor over West Africa and its relation to ENSO. Atmos. Chem. Phys. $15,2015$.

9. ZHU G.F., LI J.F., SHI P.J., HE Y.Q.,CAI A.,TONG H.L.,LIU Y.F.,YANG L. Relationship between sub-cloud secondary evaporation and stable isotope in precipitation in different regions of China. Environ Earth Sci. 75, 10, 2016.

10. ZHAO P.P., TAN L.C., ZHANG P., WANG S.J., CUI B.L., LI D., XUE G., CHENG X. Stable Isotopic Characteristics 
and Influencing Factors in Precipitation in the Monsoon Marginal Region of Northern China. Atmosphere. 9, 97, 2018.

11. CHARLES M., BALAGIZI., MARCELLIN M., KASEREKA., EMILIO C. Influence of moisture source dynamics and weather patterns on stable isotopes ratios of precipitation in Central-Eastern Africa. Science of the Total Environment, 6, 2018.

12. GUO H.W., ZHU G.F., HE Y.Q., ZHOU J.J., PAN H.X., MANG X.G., ZHANG Y., HUANG M.H., XIANG J. Dynamic characteristics and influencing factors of precipitation $\delta^{18} \mathrm{O}$, China. Theoretical and Applied Climatology. 2019.

13. FRIEDMAN L., BIGELEISEN J. Oxygen and Nitrogen Isotope Effects in the Decomposition of Ammonium Nitrate. J. Chem Phys. 18, 10, 1950.

14. YURI V., DUBLYANSKY ALEXANDER B., KLIMCHOUK L. Stable isotopic composition of atmospheric precipitation on the Crimean Peninsula and its controlling factors. J. Hydrol, 565, 2018.

15. CAI Z., TIAN L., BOWEN G.J. ENSO variability reflected in precipitation oxygen isotopes across the Asian Summer Monsoon region. Earth \& Planetary Science Letters, 475, 2017.

16. LI X., SUGimoto A., UETA A. Spatial and temporal variations of stable isotopes in precipitation in midlatitude coastal regions. Hydrological Processes, 31, 2017.

17. GH J., U S.K., B K. Variation of $\delta^{18} \mathrm{O}$ and $\delta \mathrm{D}$ in precipitation and stream waters across the Kashmir Himalaya (India) to distinguish and estimate the seasonal sources of stream flow. Journal of Hydrology, 481, 2013.

18. MULLER C.L., BAKER A., FAIRCHILD I.J., KIDD C., BOOMER I. Intra-event trends in stable isotopes: exploring mid-latitude precipita-tion using a vertically pointing micro rain radar. J Hydrometeorol. 16, 1, 2015.

19. ZHANG S., YU W.X., ZHANG Q.L., HUANG C.H., ZHANG R.S., GU Z.N., WEI Q.G., XIE Z.C., ZENG Q.Z. Distribution of radon and heavy oxygen in snow and ice in the Everest region of southern Tibet, China. Chin Sci A. 4, 1973.

20. ZHANG S., YU W.X., ZHANG Q.L., HUANG C.H., ZHANG R.S., GU Z.N., WEI Q.G., XIE Z.C., ZENG Q.Z. Distribution of radon and heavy oxygen in snow and ice in the Everest region of southern Tibet, China. Chin Sci A. 4, 1973.

21. YAO T.D., MASSON-DELMOTTE V., GAO J., YU W.S., YANG X.X., RISI C., STURM C., WERNER M., ZHAO H.B., HE Y., REN W., TIAN L.D., SHI C.M., HOU S.G. A review of climatic controls on $\delta^{18} \mathrm{O}$ in precipitation over the Tibetan Plateau: Observationsand simulations.Rev. Geophys. 51, 4, 2013.

22. LIU Q., WANG J.L., TIAN L.D., ZANG Y.L. Characteristics of Spatial Variation in Stable Isotopesin River Water Across the Qinghai-Tibetan Plateau Before the Monsoon. Journal of Southwest University(Natural Science Edition). 37, 6, 2015.

23. SUN C.J., ZHANG Z.Y., LI J., CHEN R.X., LI W. Temporal and Spatial Characteristics of Stable Isotopes of Atmospheric Precipitation in the Northwestern Tibetan Plateau. Mountain Research. 36, 2, 2018.

24. LI J.R., ZHAO J.Y., YANG L., ZHANG T.W., TSAMCHU D. Stable Hydrogen and Oxygen Isotopes in Waters in Tibet. Arid Zone Research. 34, 2, 2017.

25. YU W.S., YAO T.D., TIAN L.D., WANG Y., SUN W.Z. Oxygen-18 isotopes in precipitation on the eastern Tibetan Plateau. Annals of Glaciol. 43, 2006.
26. TIAN L.D., MASSON-DELMOTTE V., STIEVENARD M.,YAOT.D.,JOUZEL J. Tibetan Plateau summer monsoon northward extent revealed by measurements of water stable isotopes. J. Geophys. Res. 106, D22, 2012.

27. ZHANG X.P., YAO T.D. Distribution characteristics of $\delta^{18} \mathrm{O}$ in precipitation in China. J .Geogr. Sci, 53, 4, 1998.

28. LI Y.J., ZHANG M.J., WANG S.J., LI Z.Q., WANG F.T. Progress of the Resesrch of Stable Isotope in Precipitation China - A Review. J. Glaciy . Geocr. 33, 3, 2011.

29. ZHAO P.P. Characteristics of atmospheric isotopes and their influence factors in the monsoon region of northern China[D]. 2018. Northwestern University, China.

30. HE Y., RISI C., GAO J., MASSON-DELMOTTE V., YAO T.D., L C.T., DING Y.J., WORDEN J., FRANKENBERG C., CHEPFER H., CESANA G. Impact of atmospheric convection on south Tibet summer precipitation isotopologue composition using a combination of in situ measurements, satellite data, and atmospheric general circulation modeling. J. Geophys. Res. Atmos, 120, 2015.

31. MA J.Z., ZHANG P., ZHU G.F., WANG Y.Q., MIKE EDMUNDS W., DING Z.Y., HE J.H. The composition and distribution of chemicals and isotopes in precipitation in the Shiyang River system, northwestern China. Journal of Hydrology. 436/437, 2012.

32. ZHAO W., MA J.Z., GU C.J., QI S., ZHU G.F., HE J.H. Distribution of isotopes and chemicals in precipitation in ShuleRiver Basin, northwestern China: an implication for water cycle and groundwater recharge. J. Arid Land, 8, 6, 2016.

33. MA X.G., JIA W.X., ZHU G.F., DING D., PAN H.X., XU X.T., GUO H.W., ZHANG Y., YUAN R.F. Stable isotope composition of precipitation at different elevations in the monsoon marginal zone. Quat. Int, 493, 2018.

34. CHEN X., LI Z., CHEN L.P., LIU W.Z., WANG R. Hydrogen and Oxygen Stable Isotope Characteristics and Water Vapor Sources of Atmospheric Precipitation in the Loess Plateau . Journal of Ecology, 36, 1, 2016.

35. WU J.G., YANG Q.Y., DING Y.J., YE B.S., ZHANG M.Q. Variations and Simulation of Stable Isotopes in Precipitation in the Heihe River Basin. Environ. Sci, 32, 7, 2011.

36. WANG S.J., ZHANG M.J., CHE Y.J, ZHU X.F., LIU X.M. Influence of Below-Cloud Evaporation on Deuterium Excess in Precipitation of Arid Central Asia and Its Meteorological Controls. Journal of Hydrology. 17, 2016.

37. ZHU J.J., CHEN H., GONG G. Hydrogen and Oxygen Isotopic Compositions of Precipitation and Its Water Vapor Sources in Eastern Qaidam Basin. Environmental Science, 36, 8, 2015.

38. LI X.F., ZHANG M.J., LI Y.J. WANG S.J., HUANG X.Y., MA Q., MA X.N. Characteristics of $\delta^{18} \mathrm{O}$ in Precipitation and Moisture Transports over the AridRegion in Northwest China. Environment Sciences, 33, 3, 2012.

39. ZHU G.F., GUO H.W., QIN D.H., PAN H.X., ZHANG Y., JIA W.X., MA X.G. Contribution of recycled moisture to precipitation in the monsoon marginal zone: Estimate based on stable isotope data. Journal of Hydrology, 569, 2019.

40. ZHANG Y.H., WU Y.Q. Source Analysis of Atmospheric Precipitation Water Vapor in Heihe River Basin. Arid Zone Geogr, 31, 3, 2008.

41. HU J., LV Y.H., ZHANG K., TAO Y.Z., LI T., REN Y.J. Differences in water conservation functions of typical vegetation types in the Pai'ergou watershed of Qilian Mountains. J.Ecology, 36, 11, 2016. 
42. WANG Y.Q., ZHANG J.J., LI L., ZHOU Y.P., ZHANG S.H., CHEN B.Q., ZHAO R.W., SUN R.X., RU H. Soil impact factors of typical grassland ecosystems in Qilian Mountains . J. Ecolog, 38, 1, 2018.

43. ZHEN L., HU Y.F., WEI Y.J., L Q., HAN Y.Q. Trend of ecological degradation and restoration technology requirement in typical ecological vulnerable regions. Resources Science. 41, 1, 2019.

44. WANG X.L. Study on Mountain Climate of Xiying River Basin in Shandong Section of Qilian [D]. 2014, Lanzhou University, China.

45. Shiyang River Water Resources Bulletin 2015. http://www. gssl.gov.cn/syhglj/ztzl/sy.(accessed 22July 2018)

46. CRAIG H. Isotopic variations in meteoric waters. Science, 133, 3465, 1961.

47. DRAXLER R.R., HESS G. An overview of the HYSPLIT_4 modelling system for trajectories, dispersion, and deposition. Australian Meteo-rological Magazine, 47, 1998.

48. ZHAO W., HAO C.Y., XU C.Y. Identification of Interaction Region Influenced by Different Summer Monsoons of China Based on HYSPLIT Model. Geography and GeoInformation Science, 34, 2, 2018.

49. WANG X.Y., LU A.G., JIANG C.W., WANG S.A., LIU H. Relationship between Hydrogen and Oxygen Isotope Characteristics and Water Vapor Sources in Atmospheric
Precipitation in Southern Anhui Province . Journal of Arid Land Resources and Environment, 31, 8, 2017.

50. GU W.Z. Isotope Hydrology [M].Science press, Beijing. P123-124.2011.

51. LI W.J., WANG J.L., WANG J.L. Characteristics of the Stable Isotopes in Precipitation and the Source of Water Vapor in Different Terrain in the Southwest Region.[J] Resources and Environment in the Yangtze Basin, 27, 5, 2018.

52. LIU J.R., SONG X.F., SUN X.M.,YUAN G.F., LIU X., WANG S.Q. Isotopic composition of precipitation over Arid Northwestern China and its implications for the water vapor origin. J. Geogr. Sci, 63, 1, 2014.

53. PANG Z.H., KONG Y.L., FROEHLICH K., HUANG T.M., YUAN L.J., LI Z., WANG F.T. Processes affecting isotopes in precipitation of an arid region. Tellus $\mathrm{B}, \mathbf{6 3}, 3$, 2011.

54. JOUZEL J., MERLIVAT L. Deuterium and oxygen 18 in precipitation: Modeling of the isotopic effects during snow formation. J of Geophys Res, 89, D7, 1984.

55. ROZANSKI K., ARAGUAS-ARAGUAS L., GONFIANTINI R. Relation between long-term trends of oxygen-18 isotope composition of precipitation and climate. Science, 258, 5084, 1992.

56. ZHANG X.W. Vertical distribution of airflow to matter and energy delivery. Desert And Oasis Weather, 2, 2009. 
